\title{
Current clues for better analgesic prescription after urologic surgery
}

\author{
María Rodríguez-Cabero, Javier González \\ Servicio de Urología, Hospital General Universitario Gregorio Marañón, Madrid, Spain \\ Correspondence to: Dr. Javier González, MD, PhD. Servicio de Urología, Hospital General Universitario Gregorio Marañón, C/Dr Esquerdo, 46, \\ 28007 Madrid, Spain. Email: fjgg1975@yahoo.com. \\ Comment on: Welk B, McClure JA, Clarke C, et al. An Opioid Prescription for Men Undergoing Minor Urologic Surgery Is Associated with an \\ Increased Risk of New Persistent Opioid Use. Eur Urol 2020;77:68-75.
}

Submitted May 20, 2020. Accepted for publication Jun 01, 2020.

doi: 10.21037/tau-20-937

View this article at: http://dx.doi.org/10.21037/tau-20-937

Recently, Welk and coworkers (1) published a retrospective cohort study aimed to determine whether a first time prescription of opioids to patients following minor urologic surgery was associated with new persistent opioid use. They include patients $\geq 18$ years of age from the province of Ontario (Canada) who underwent a specific urologic procedure in a 4-year period [2013-2016], excluding those patients who were using opioids for long before the intervention ( $>180$ days), having a prolonged hospitalization after the procedure, and visiting the emergency around the date of the procedure.

Data for analysis were routinely collected at a populationlevel, and based on commonly used local prescription practices (i.e., non-requiring opioids: transurethral resection of the prostate, internal urethrotomy, and vasectomy). The exposure to evaluate opioid maintenance was defined by those patients filling an initial opioid prescription, and filling thereafter at least two additional prescriptions in the period of 15 months after the procedure of interest. Visits to emergency facilities regarding an opioid overdose in this interval were also recorded. In addition to demographics and conventional comorbidities (heart and lung disease, alcoholism and rheumatoid arthritis), other special comorbid conditions that commonly require opioid use (head trauma, osteoarthritis, mental disorders, chronic pain, and fibromyalgia) were included as potential confounders.

Welk et al. (1) finally included a total of 91,083 candidates meeting the inclusion criteria, and 430 prescribing physicians. Vasectomy was the most frequent intervention conducted, however only $56 \%$ of them were performed by urologists. Primary care physicians and other specialists performed a non-negligible $44 \%$ of the procedures.

A significant $35 \%$ of the patients evaluated filled a prescription within the 5 days from the surgery date. The most commonly prescribed drugs included immediate release codeine, oxycodone, and tramadol. Those patients filling an initial opioid prescription presented a higher American Society of Anesthesiologists (ASA) score and attended more frequently to a presurgical anesthesiology visit. Probably, most of the opioids in these patients were prescribed by the anesthesiologist. Therefore, those interventions requiring anesthesia (i.e., hydrocelectomy, spermatocelectomy, and circumcision) were the procedures in which the majority of the opioids prescriptions were filled. Conversely, anesthesia in the vasectomy procedure is commonly provided by the surgeon himself.

There was a very low proportion $(1.4 \%)$ of patients unexposed to opioids in this study, a figure that gives an idea of the high prevalence of opioid use in real practice. Regarding vasectomy, the median equivalent dose with morphine administered reached an astonishing $113 \mathrm{mg}$; much higher than that required for minimally invasive procedures in general surgery $(30 \mathrm{mg})$, or radical prostatectomy $(23 \mathrm{mg})$. Undoubtedly, this excess of opioid prescription is a potential source of abuse.

Surprisingly, the vast majority of those filling prescriptions for vasectomies were administered by urologists, instead of primary care physicians or other specialists. Men receiving a first prescription were at significantly higher risk of developing maintenance and 
overdose. The authors demonstrated $43 \%$ increased odds of new persistent opioid use when opioid-naïve patients filled an initial prescription for these drugs, compared with similar patients who underwent the same procedures but did not filled the prescription. An increased risk of hospitalization for opioid overdose was also observed, although the absolute risk of this outcome was quite low $(0.02 \%)$, being similar to that observed in the Canadian general population.

The authors concluded that urologists with their prescriptions are playing a major role in opioid maintenance and overdose. They also highlighted that many minor procedures in Urology do not require opioids in the postoperative period, recommending putting limits on their use through better education of the trainees, lowering the default pill count in electronic medication records, or regulatory interventions.

To date, opioids remain the cornerstone of postoperative pain management. However, opioid use has turned into an emergent epidemic, representing a major public healthcare concern, particularly in the United States. From 1999 to 2017, the number of deaths from overdoses in relation to opioid prescription has multiplied by 4 -fold in this country (2). Canada has also seen a significant increase in recent years, as evidenced by the second highest rate of opioid prescription worldwide. Although Europe has also been a first-line spectator for this increase in the past few years, it has been reported to be lower in magnitude, and fortunately has not translated into a parallel increase of opioidrelated morbidity and mortality by the moment. Even so, European health authorities must be warned and alert to this threatening problem.

Significant differences in prescription regulations, attitude towards medical and non-medical use of these drugs, publicity in the media, cultural habits, and availability of illicit psychotropics, are among others, some of the factors that have been proposed to explain the differences observed between countries (3). Undoubtedly, this trend relies also on the lack of accurate recommendations existing in regards to appropriate drug prescription after surgery. Therefore, surgeons still prescribe them frequently, despite the fact that much of this medication is neither required nor even used after a planned surgical intervention (4).

For many patients, acute postoperative pain represents the first exposure to opioids, and for some of them, simple exposure can lead to a medication misuse (5). In addition, a higher opioid prescription at discharge associates greater use regardless the diagnosis, thus suggesting that drug accessibility would play a central role in excessive use, rather than other clinical or surgical factors. Furthermore, a substantial percentage of patients receiving opioids for postoperative pain control, do not dispose of the medication properly, keeping it at home after the convalescence period, and favoring in a recent study an amazing $55 \%$ of opioid-abuse cases coming from legal prescriptions made for a relative or friend (6). In the light of the reported experiences, what seems clear is that excessive postoperative opioid prescription may induce persistent use and longterm addiction in some patients (7).

Urology, like any other surgical specialty, is not an exception. Opioid prescription after urological surgery is rather common. For instance, vasectomy is the most frequently performed urological intervention in the US (8). Recent evidence have shown that in up to $50 \%$ of these procedures, opioids are prescribed for postoperative pain control by urologists, primary care physicians, and other specialists (9). Conversely, only $41 \%$ of those patients that underwent a vasectomy in whom opioids were prescribed, actually use them, meaning that a large amount of narcotics is presumably prescribed unnecessarily. Therefore, urologists have a crucial role in reducing opioid prescription.

Although the American Urological Association (AUA) guidelines encourages the use of non-opioid analgesics in pain management, no specific recommendations for postoperative pain control is provided (10). Similarly, the European Association of Urology (EAU) guidelines recommend in favor of multimodal analgesia, and against the use of opioids in both immediate and long-term postoperative pain control (11). Probably, a better definition of optimal postoperative pain management focused on specific categories (groups of urological procedures according to pain severity and/or postoperative analgesic requirements), would be a valuable tool in limiting excessive opioid prescription.

In this sense, the use of preemptive analgesia (i.e., administered before the painful stimulus in order to decrease subsequent pain and analgesic requirements after the stimulus), and various opioid-saving techniques have been described including the use of local/regional anesthetics (i.e., lidocaine, mepivacaine, bupivacaine), and the so-called multimodal analgesia for postoperative pain management. Although the use of local and regional anesthesia (i.e., epidural, perineural and infiltrative techniques) is increasing, this type of analgesia is administered in an outpatient hospital/clinic setting, and 
Table 1 Outcomes of current studies evaluating the use of different opioid-saving techniques in opposition to opioid-based regimes in urologic surgery

\begin{tabular}{|c|c|c|c|c|c|}
\hline Author & Year & $\begin{array}{l}\text { Surgical } \\
\text { procedure }\end{array}$ & Analgesic schedule & Feedback & Outcome \\
\hline $\begin{array}{l}\text { Mehta A, } \\
\text { et al. (3) }\end{array}$ & 2013 & $\begin{array}{l}\text { Microsurgical } \\
\text { testicular sperm } \\
\text { extraction }\end{array}$ & $\begin{array}{l}\text { Celecoxib } 200 \text { mg/12 h + paracetamol } \\
\text { vs. oxycodone vs. placebo }\end{array}$ & $\begin{array}{l}\text { Daily VAS for } 7 \text { days, } \\
\text { and opioid registry at } \\
\text { discharge }\end{array}$ & Lower VAS with celecoxib \\
\hline $\begin{array}{l}\text { Haswir } \mathrm{H}, \\
\text { et al. (4) }\end{array}$ & 2008 & Prostate biopsy & $\begin{array}{l}\text { Diclofenac } 100 \mathrm{mg} \text { rectal vs. } 10 \mathrm{mg} \\
\text { morphine }\end{array}$ & VAS after the procedure & No significant differences \\
\hline $\begin{array}{l}\text { Ellis JL, } \\
\text { et al. (7) }\end{array}$ & 2020 & $\begin{array}{l}\text { Penile prosthesis } \\
\text { implant }\end{array}$ & $\begin{array}{l}\text { Paracetamol } 975 \mathrm{mg} / 6 \mathrm{~h}+\text { gabapentin } \\
300 \mathrm{mg} / 8 \mathrm{~h}+15 \mathrm{mg} \text { meloxicam } / 24 \mathrm{~h}+ \\
\text { lidocaine/bupivacaine intraoperatively } \\
\text { vs. oxycodone } 5 \mathrm{mg} / 4 \mathrm{~h}\end{array}$ & $\begin{array}{l}\text { VAS after the procedure } \\
\text { and PO day } 1 \text {, opioid } \\
\text { registry at discharge }\end{array}$ & $\begin{array}{l}\text { Lower VAS, lower opioid use, } \\
\text { and lower refills with the } \\
\text { opioid-free regime }\end{array}$ \\
\hline $\begin{array}{l}\text { Lucas J, } \\
\text { et al. (8) }\end{array}$ & 2020 & $\begin{array}{l}\text { Penile prosthesis } \\
\text { implant }\end{array}$ & $\begin{array}{l}\text { Paracetamol } 975 \text { mg/6 h + gabapentin } \\
300 \mathrm{mg} / 8 \mathrm{~h}+15 \mathrm{mg} \text { meloxicam/24 h, } \\
\text { intraoperative lidocaine/bupivacaine, } \\
\text { oxycodone } 5 \mathrm{mg} / 4 \mathrm{~h} \text { OD, vs. opioid } \\
\text { based analgesia }\end{array}$ & $\begin{array}{l}\text { VAS after the procedure } \\
\text { and PO day } 1 \text {, opioid } \\
\text { registry at discharge }\end{array}$ & $\begin{array}{l}\text { Lower VAS, lower opioid use, } \\
\text { and lower refills with the } \\
\text { opioid-free regime }\end{array}$ \\
\hline $\begin{array}{l}\text { Dam M, } \\
\text { et al. (9) }\end{array}$ & 2019 & $\begin{array}{l}\text { Percutaneous } \\
\text { nephrolithotomy }\end{array}$ & $\begin{array}{l}\text { Preoperative paracetamol } 1 \mathrm{~g} \mathrm{+} \\
\text { dexamethasone } 4 \mathrm{mg},+ \text { sufentanil } \\
0.25 \mathrm{mg} / \mathrm{kg} \text {, transmuscular blockage, } \\
\text { ropivacaine + paracetamol } 1 \mathrm{~g} / 6 \mathrm{~h} \text {, vs. } \\
\text { placebo + paracetamol } 1 \mathrm{~g} / 6 \mathrm{~h}\end{array}$ & $\begin{array}{l}\text { Oral morphine } \\
\text { equivalent use, VAS at } \\
\text { discharge }\end{array}$ & $\begin{array}{l}\text { Lower opioid use, shorter time } \\
\text { to discharge, longer time to first } \\
\text { opioid prescription, and lower } \\
\text { VAS for the opioid-free schedule }\end{array}$ \\
\hline $\begin{array}{l}\text { Cacciamani } \\
\text { GE, et al. } \\
\text { (11) }\end{array}$ & 2019 & $\begin{array}{l}\text { Radical } \\
\text { prostatectomy }\end{array}$ & $\begin{array}{l}\text { Blockage with ropivacaine }+ \\
\text { paracetamol } 1 \mathrm{~g} / 8 \mathrm{~h}+\text { tramadol OD vs. } \\
\text { placebo }+ \text { paracetamol } 1 \mathrm{~g} / 8 \mathrm{~h}+ \\
\text { tramadol OD }\end{array}$ & $\begin{array}{l}\text { VAS/8 } \mathrm{h} \text { during } \\
\text { admission opioid } \\
\text { demand }\end{array}$ & $\begin{array}{l}\text { Lower opioid use in the } \\
\text { postoperative period, lower VAS } \\
\text { with blockage }\end{array}$ \\
\hline
\end{tabular}

PO, postoperative; OD, on demand; VAS, visual analgesic score.

probably results less subject to patient misuse or overdose. On the other hand, multimodal analgesia consists of the synchronic combination of different painkillers acting through different mechanisms to produce analgesic synergy. Paracetamol, selective and non-selective ciclooxygenase-2 (COX-2) inhibitors, ketamine, and different antiepileptics (i.e., gabapentin and pregabalin) are commonly combined in this analgesic modality.

Table 1 shows the outcomes of current studies evaluating the use of different opioid-saving techniques in opposition to opioid-based regimes in urologic surgery. Evidence drawn from these studies recommends to avoid completely the use of opioids in minor surgery. Alternatively, management of postoperative pain should be performed 
using non-steroidal anti-inflammatory drugs (NSAIDs), paracetamol, local anesthetics (depending on the surgical area), or a combination of them. Similar or even better pain control, in base of the results obtained through the visual analgesic scale (VAS), has been achieved with the opioidfree regime in these cases.

Regarding more invasive procedures (i.e., endoscopic, laparoscopic/robotic assisted, or open surgical interventions), the available evidence shows clear benefit in favor of multimodal analgesia. A myriad of studies reporting better pain control through the use of local/regional anesthetics at the end of the procedure (i.e., surgical wound or trocar incisions infiltration, regional blockage), and a combination of NSAIDs, paracetamol, and gabapentinoids during the immediate postoperative period and after discharge are available. In these type of procedures, the goal should be to decrease the use of opioids, but not eliminate it entirely. For instance, opioids may be recommended for salvage pain control (only whenever deemed necessary), during the immediate postoperative period. Oral intake (when possible) should be preferable over venous infusion, and patient controlled analgesia (PCA) devices would represent the best choice for their endovenous administration.

Other evidence-based recommendations include: the assessment of preoperative analgesic administration whenever possible, and the adaptation of the drug regime to the pain type and unique features.

In summary, the indiscriminate use of opioids is a major public health concern. The lack of accurate best practice guidance may perpetuate this problem over time. Postoperative pain management is possible with opioidfree regimes. Although opioids may be used under certain circumstances, surgeons must be aware of the problems derived from their excessive use, thus trying to limit their prescription. Preemptive analgesia, adaptation to pain characteristics, and a combination of paracetamol, NSAIDs, gabapentinoids, and local anesthetics must be always considered a valuable option to be used during the postoperative period of every urologic surgical patient.

\section{Acknowledgments}

Funding: None.

\section{Footnote}

Provenance and Peer Review: This article was commissioned by the editorial office, Translational Andrology and Urology. The article did not undergo external peer review.

Conflicts of Interest: Both authors have completed the ICMJE uniform disclosure form (available at http://dx.doi. org/10.21037/tau-20-937). The authors have no conflicts of interest to declare.

Ethical Statement: The authors are accountable for all aspects of the work in ensuring that questions related to the accuracy or integrity of any part of the work are appropriately investigated and resolved.

Open Access Statement: This is an Open Access article distributed in accordance with the Creative Commons Attribution-NonCommercial-NoDerivs 4.0 International License (CC BY-NC-ND 4.0), which permits the noncommercial replication and distribution of the article with the strict proviso that no changes or edits are made and the original work is properly cited (including links to both the formal publication through the relevant DOI and the license). See: https://creativecommons.org/licenses/by-nc-nd/4.0/.

\section{References}

1. Welk B, McClure JA, Clarke C, et al. An Opioid Prescription for Men Undergoing Minor Urologic Surgery Is Associated with an Increased Risk of New Persistent Opioid Use. Eur Urol 2020;77:68-75.

2. Leung PTM, Macdonald EM, Stanbrook MB, et al. A 1980 Letter on the Risk of Opioid Addiction. N Engl J Med 2017;376:2194-5.

3. Mehta A, Hsiao W, King P, et al. Perioperative celecoxib decreases opioid use in patients undergoing testicular surgery: a randomized, double-blind, placebo controlled trial. J Urol 2013;190:1834-8.

4. Haswir H, Umbas R. Comparison of efficacy between oral morphine sulphate and diclofenac suppository for analgesia during transrectal ultrasound-guided prostate biopsy. Acta Med Indones 2008;40:124-8.

5. Hashem A, Ghobrial FK, Elbaset MA, et al. Efficacy of pethidine, ketorolac, and lidocaine gel as analgesics for pain control in shockwave lithotripsy: A singleblinded randomized controlled trial. Investig Clin Urol 2019;60:251-7.

6. Tong CMC, Lucas J, Shah A, et al. Novel Multi-Modal Analgesia Protocol Significantly Decreases Opioid Requirements in Inflatable Penile Prosthesis Patients. J 
Sex Med 2018;15:1187-94.

7. Ellis JL, Higgins AM, Simhan J. Pain management strategies in penile implantation. Asian J Androl 2020;22:34-8.

8. Lucas J, Gross M, Yafi F, et al. A Multi-institutional Assessment of Multimodal Analgesia in Penile Implant Recipients Demonstrates Dramatic Reduction in Pain Scores and Narcotic Usage. J Sex Med 2020;17:518-25.

9. Dam M, Hansen CK, Poulsen TD, et al. Transmuscular quadratus lumborum block for percutaneous nephrolithotomy reduces opioid consumption and speeds ambulation and discharge from hospital: a single centre randomised controlled trial. Br J Anaesth

Cite this article as: Rodríguez-Cabero M, González J. Current clues for better analgesic prescription after urologic surgery. Transl Androl Urol 2020;9(6):2462-2466. doi: 10.21037/tau-20-937 2019;123:e350-e358.

10. Hatipoglu Z, Gulec E, Turktan M, et al. Comparative study of ultrasound-guided paravertebral block versus intravenous tramadol for postoperative pain control in percutaneous nephrolithotomy. BMC Anesthesiol 2018;18:24.

11. Cacciamani GE, Menestrina N, Pirozzi M, et al. Impact of Combination of Local Anesthetic Wounds Infiltration and Ultrasound Transversus Abdominal Plane Block in Patients Undergoing Robot-Assisted Radical Prostatectomy: Perioperative Results of a Double-Blind Randomized Controlled Trial. J Endourol 2019;33:295-301. 